
\title{
R Reserarch Soure \\ Effect of LiNbO3 on the Electrocaloric Performance of 0.94BNT-0.06BT Ceramic Materials
}

\section{Jing Chen ( $\nabla$ chenjing@niit.edu.cn )}

Nanjing Vocational University of Industry Technology https://orcid.org/0000-0003-3893-4952

lei Wu

Nanjing Vocational University of Industry Technology

\section{Luanfan Duan}

Nanjing Vocational University of Industry Technology

Dongren Liu

Yangzhou University

\section{Research Article}

Keywords: (Bi0.5Na0.5)TiO3-BaTiO3, Electrocaloric effect, Lead-free piezoelectric

Posted Date: April 20th, 2021

DOl: https://doi.org/10.21203/rs.3.rs-437223/v1

License: (9) This work is licensed under a Creative Commons Attribution 4.0 International License.

Read Full License

Version of Record: A version of this preprint was published at Ferroelectrics on December 10th, 2021. See the published version at https://doi.org/10.1080/00150193.2021.1991207. 


\title{
Effect of $\mathrm{LiNbO}_{3}$ on the Electrocaloric Performance of 0.94BNT- 0.06BT Ceramic Materials
}

\author{
Jing Chen ${ }^{l^{*}}$, Lei Wu ${ }^{l}$, Luanfang Duan ${ }^{l}$ and Dongren Liu ${ }^{2}$
}

1. School of Electrical Engineering, Nanjing Vocational University of industry Technology, No. 1 Yang Shan North Road, Nanjing 210046, P. R. China.

2. Mechanical Engineering college, Yangzhou University, 88 South University Ave., Yangzhou 225009, P. R. China.

* Correspondence: chenjing@niit.edu.cn (Jing Chen)

Keywords: ( $\left.\mathrm{Bi} 0.5 \mathrm{Na}_{0.5}\right) \mathrm{TiO}_{3}-\mathrm{BaTiO}_{3}$, Electrocaloric effect, Lead-free piezoelectric

\section{Abstract}

Considering that the electric refrigeration temperature range of $0.94 \mathrm{BNT}-0.06 \mathrm{BT}$ ceramic materials is $100 \sim 140^{\circ} \mathrm{C}$, the electric refrigeration performance of the $0.94 \mathrm{BNT}-$ 0.06BT ceramic material system was modified by $\mathrm{LiNbO}_{3}$ doping to reduce the cooling temperature. As a result, the refrigeration temperature range of the 0.94BNT-0.06BT ceramic material system was lowered to $25 \sim 80^{\circ} \mathrm{C}$, achieving its cooling effect near room temperature, and in this temperature range, the adiabatic temperature changes $\Delta \mathrm{T}>0.6 \mathrm{~K}$.

\section{Introduction}

Currently, $\mathrm{Bi}_{0.5} \mathrm{Na}_{0.5} \mathrm{TiO}_{3}(\mathrm{BNT})$ perovskite-type relaxor ferroelectrics have become one of the popular material systems under electrocaloric effect research owing to their large pyroelectric coefficient, wide phase transition temperature zone and phase transition temperature adjustability. In 2014, Jiang et al. ${ }^{[1]}$ discovered a large electrocaloric effect in the $\mathrm{BNT}-\mathrm{kNbO}_{3}(\mathrm{KN})$ binary system. 0.94BNT-0.06KN has a drastic adiabatic temperature change $\Delta T_{\max }=1.73 \mathrm{~K}$ at $76^{\circ} \mathrm{C}$ near the temperature at 
which the ferroelectric phase is transformed into the relaxor ferroelectric phase. In 2016, $\mathrm{Ca}$ et al. found that $0.75 \mathrm{BNT}-0.25 \mathrm{ST}$ has a high positive electrocaloric effect at $60^{\circ} \mathrm{C}$ and $50 \mathrm{kV} / \mathrm{cm}$ near the morphotropic phase boundary (MPB) of the BNT-ST binary ceramic material, and its adiabatic temperature change $\Delta T_{\max }=1.64 \mathrm{~K}$. Moreover, the adiabatic temperature change of $0.74 \mathrm{BNT}-0.26 \mathrm{ST}$ in the temperature range of $30 \sim 70^{\circ} \mathrm{C}$ is greater than $1 \mathrm{~K}$, suggesting that it has a wide temperature range, which is suitable for the actual application of this material. In 2011, Bai ${ }^{[2]}$ and Zhen et al. ${ }^{[3]}$ found that the materials in the BNT-BT binary system have an electrocaloric effect. Among these materials, $0.92 \mathrm{BNT}-0.08 \mathrm{BT}$ has a negative electrocaloric effect at $140^{\circ} \mathrm{C}$ and $50 \mathrm{kV} / \mathrm{cm}$, and $\Delta T=0.33 \mathrm{~K}$. In 2016 , $\mathrm{Li}$ et al. found that doped with $0.5 \mathrm{wt} \% \mathrm{La}_{2} \mathrm{O}_{3}$, the material has a high electrocaloric effect near the MPB of $0.94 \mathrm{BNT}-0.06 \mathrm{BT}$, and that at $62^{\circ} \mathrm{C}$, the adiabatic temperature change of the material, $\Delta T_{\max }=2.61 \mathrm{~K}$. This is equivalent to the maximum adiabatic phase transition of the lead-based material relaxor ferroelectric 0.71PMN-0.29PT. Later, a lot of literature ${ }^{[4-8]}$ reported $0.94 \mathrm{BNT}-0.06 \mathrm{BT}$ and the electrocaloric effect of a doping material. The pure 0.94BNT-0.06BT is a relaxor ferroelectric, and there is a phase transition from the ferroelectric to a relaxor at $100 \sim 140^{\circ} \mathrm{C}$; at $5 \mathrm{kV} / \mathrm{cm}$, the $\Delta T$ of all materials is greater than $0.6 \mathrm{~K}$. Besides, the calculated adiabatic temperature change is basically the same as the actual adiabatic temperature change.0.94BNT-0.06BT is a relaxor ferroelectric. There is a phase transition from ferroelectric phase to relaxor phase between 100 and $140^{\circ} \mathrm{C}$. The same conclusion can be drawn by both direct testing and calculation. At $5 \mathrm{kV} / \mathrm{cm}$ and $100 \sim 140^{\circ} \mathrm{C}$, the material has a great electrocaloric effect. Its adiabatic temperature 
change $\Delta \mathrm{T}$ is greater than $0.6 \mathrm{~K}$. However, common refrigeration materials are all used near room temperature. The previous study ${ }^{[9]}$ show that $\mathrm{LiNbO}_{3}$ doping can reduce the temperature of the material during the transition from the ferroelectric phase to the relaxor phase. Given doping quantity of $0.025 \mathrm{~mol}$, the temperature of the material during the transition from the ferroelectric phase to the relaxor phase is near room temperature. Therefore, based on the previous research findings, the present section explores the influence of $\mathrm{LiNbO}_{3}$ on the electrocaloric effect of $0.94 \mathrm{BNT}-0.06 \mathrm{BT}$.

\section{Experiments}

(1) Sample Preparation

The specimens of $(1-\mathrm{x})(0.94 \mathrm{BNT}-0.06 \mathrm{BT})-\mathrm{xLiNbO} 3$ piezoelectric ceramics were prepared by conventional ceramic fabrication process. The high-purity oxide and carbonate powders of $\mathrm{Bi}_{2} \mathrm{O}_{3}, \mathrm{TiO}_{2}, \mathrm{Na}_{2} \mathrm{CO}_{3}, \mathrm{BaCO}_{3}, \mathrm{Li}_{2} \mathrm{CO}_{3}, \mathrm{Nb}_{2} \mathrm{O}_{5}$ were used as raw materials and were weighed according to the stoichiometric formula. To acquire homogeneous mixed powders, the powders were mixed with Zirconia ball and anhydrous ethanol in agate jar more than the 8 hours. The mixture were calcined at $800{ }^{\circ} \mathrm{C}$ for 2 hours after dried under $80{ }^{\circ} \mathrm{C}$. After re-milling, the powders were pressed into $13 \mathrm{~mm}$ diameter pellets with 5\% polyvinyl alcohol (PVA) under $150 \mathrm{Mpa}$. After burning off PVA, the ceramics were sintered in a alumina crucible at $980-1180{ }^{\circ} \mathrm{C}$ for 2 hours in air. In order to avoid the evaporation of Bismuth and Sodium, the pellets were embedded into the same composition powder. To test dielectric and ferroelectric properties, the sintered samples were polished into $1 \mathrm{~mm}$ thickness and a diameter of 2 $\mathrm{cm}$. Silver electrodes were pasted on top and bottom surfaces and fired 10 minutes at 
$700^{\circ} \mathrm{C}$.

(2) Measurements

The ferroelectric hysteresis loops were measured at $1 \mathrm{~Hz}$ in silicon oil by a ferroelectric test system(Radiant Technologies.INC, Model: P-PMF). Determination of density by Archimedes drainage. The Specific heat capacity were measured by DSC.

\section{Rusults and Discussion}

The cycle for direct testing of the electrocaloric effect is very long and the equipment is quite expensive. Thus, an indirect method, including Maxwell's relation and thermodynamic equation, is used to calculate the electrocaloric effect of (1$\mathrm{x})(0.94 \mathrm{BNT}-0.06 \mathrm{BT})-\mathrm{xLiNbO}$. According to Equation $\Delta S=\int_{E_{1}}^{E_{2}}\left(\frac{\partial P}{\partial T}\right)_{E} d E \quad$ and $\Delta T=-\frac{T}{\rho} \int_{E_{1}}^{E_{2}} \frac{1}{C_{E}}\left(\frac{\partial P}{\partial T}\right)_{E} d E$, the electrocaloric effect of the material needs to be calculated based on the ferroelectric hysteresis loop of the material at different temperatures. In the present section, at $60 \mathrm{kV} / \mathrm{cm}$ and $20^{\circ} \mathrm{C} \sim 160^{\circ} \mathrm{C}$, the samples undergo a ferroelectric hysteresis loop test based on the results of the phase transition temperature obtained in the dielectric test conducted in the previous study ${ }^{[9]}$. In order to accurately calculate the adiabatic change temperature of the material, temperature measurement is carried out every $10^{\circ} \mathrm{C}$ in the present section. Figure 1 shows the ferroelectric hysteresis loop of the material at different temperatures. As shown in Figure $1,0.99(0.94 \mathrm{BNT}-0.06 \mathrm{BT})-0.01 \mathrm{LiNbO}_{3}$ is a typical ferroelectric. As the temperature rises, both remanent polarization and coercive field strength decrease, with the material characterized by double hysteresis loop. This indicates that the ferroelectric 
phase has been changed to the relaxor phase. According to the dielectric properties of materials presented in the previous study ${ }^{[9]}$, the ferroelectric phase is changed to the relaxor phase at about $74^{\circ} \mathrm{C}$. As the temperature continues to rise, the material becomes an elongated quasi-linear hysteresis loop, indicating that the material is in a completely relaxed state at this time. According to literature reports ${ }^{[8,10,11]}$, a huge electrocaloric effect usually occurs during the transition from the ferroelectric phase to the relaxor phase. Therefore, an emphasis is laid on the electrocaloric effect occurring at the phase transition point. With the increase in the content of $\mathrm{LiNbO}_{3}$, the temperature of the material decreases steadily during the transition from the ferroelectric phase to the relaxor phase, and the phase transition temperature decreases to about $50^{\circ} \mathrm{C}$ at 0.015 mol. The phase transition temperature is around $40^{\circ} \mathrm{C}$ at $0.02 \mathrm{~mol}$; the phase transition temperature drops near room temperature at $0.025 \mathrm{~mol}$, with the material at the critical point between the ferroelectricity and relaxation. So, our research continues till the content of $\mathrm{LiNbO}_{3}$ decreases to $0.025 \mathrm{~mol}$. 

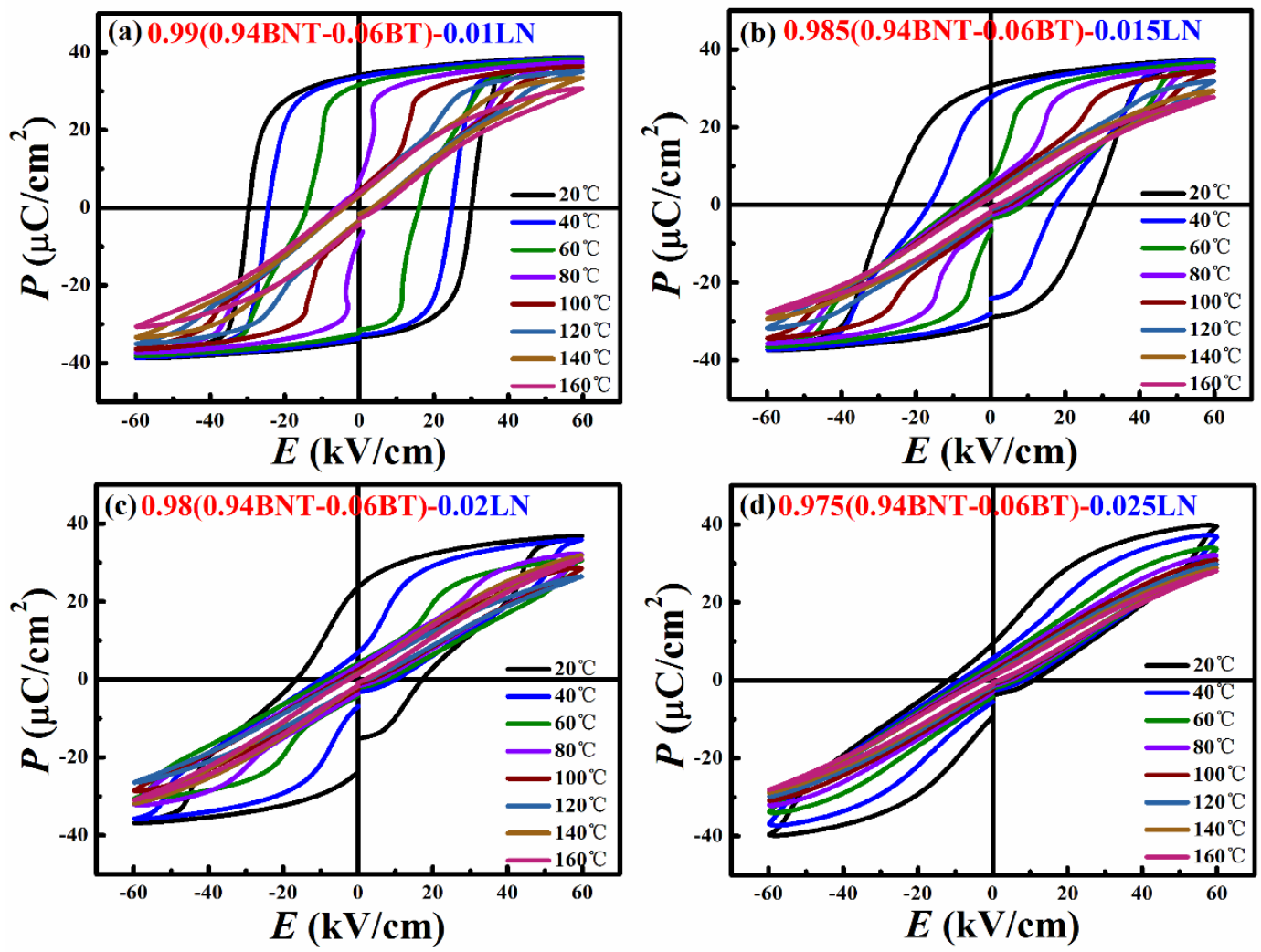

Figure 1. Variable-temperature ferroelectric hysteresis loop of (1-x)(0.94BNT-

0.06BT)-xLiNbO 3 at different temperatures: (a) $0.01 \mathrm{LiNbO}_{3}$; (b) $0.015 \mathrm{LiNbO}_{3}$; (c) $0.02 \mathrm{LiNbO}_{3} ;$ (d) $0.025 \mathrm{LiNbO}_{3}$.

In order to calculate adiabatic temperature changes using Equation $\Delta T=-\frac{T}{\rho} \int_{E_{1}}^{E_{2}} \frac{1}{C_{E}}\left(\frac{\partial P}{\partial T}\right)_{E} d E$, we have drawn the curves of variation between the maximum polarization and temperature in different electric fields. As shown in Figure 2, the electric field strength corresponding to the curves in the figure is $0,10,20,30$, 40, 50, and $60 \mathrm{kV} / \mathrm{cm}$, respectively. As can be seen in the figure, the maximum polarization shows a decreasing trend for each component. For the material 0.99(0.94BNT-0.06BT)-0.01 $\mathrm{LiNbO}_{3}$, when a low electric field of 0,10 and $20 \mathrm{kV} / \mathrm{cm}$ is applied, the maximum polarization of the material decreases sharply with the increasing temperature, especially at $0 \mathrm{kV} / \mathrm{cm}$, decreasing from $34 \mu \mathrm{C} / \mathrm{cm}^{2}$ to $4 \mu \mathrm{C} / \mathrm{cm}^{2}$ 
or so. At $30,40,50$ and $60 \mathrm{kV} / \mathrm{cm}$, the maximum polarization of the material does not fall sharply, and just decreases slowly with the rise in temperature. This is because the transition between the ferroelectric phase and the relaxor phase can be accompanied by depolarization transition in a low electric field, while there is no such depolarization transition in a high field ${ }^{[5]}$. Given a certain electric field, the saturated polarization increases with the temperature. The more drastic the change is, the greater the change in entropy of the ceramic material is, and the greater the adiabatic temperature change is. Therefore, the electrocaloric effect of the material near transition between the ferroelectric phase and the relaxor phase can be improved. With the increase in the doping content of $\mathrm{LiNbO}_{3}$, the maximum polarization of the material decreases less and less sharply with increasing temperature in a low electric field. The maximum polarization of the material barely tends to change suddenly when the content of $\mathrm{LiNbO}_{3}$ declines to 0.025 , while only some traces of change can be seen. The maximum polarization just shows slow downward trend as the temperature increases. This indicates that this type of transition has dropped near room temperature. 

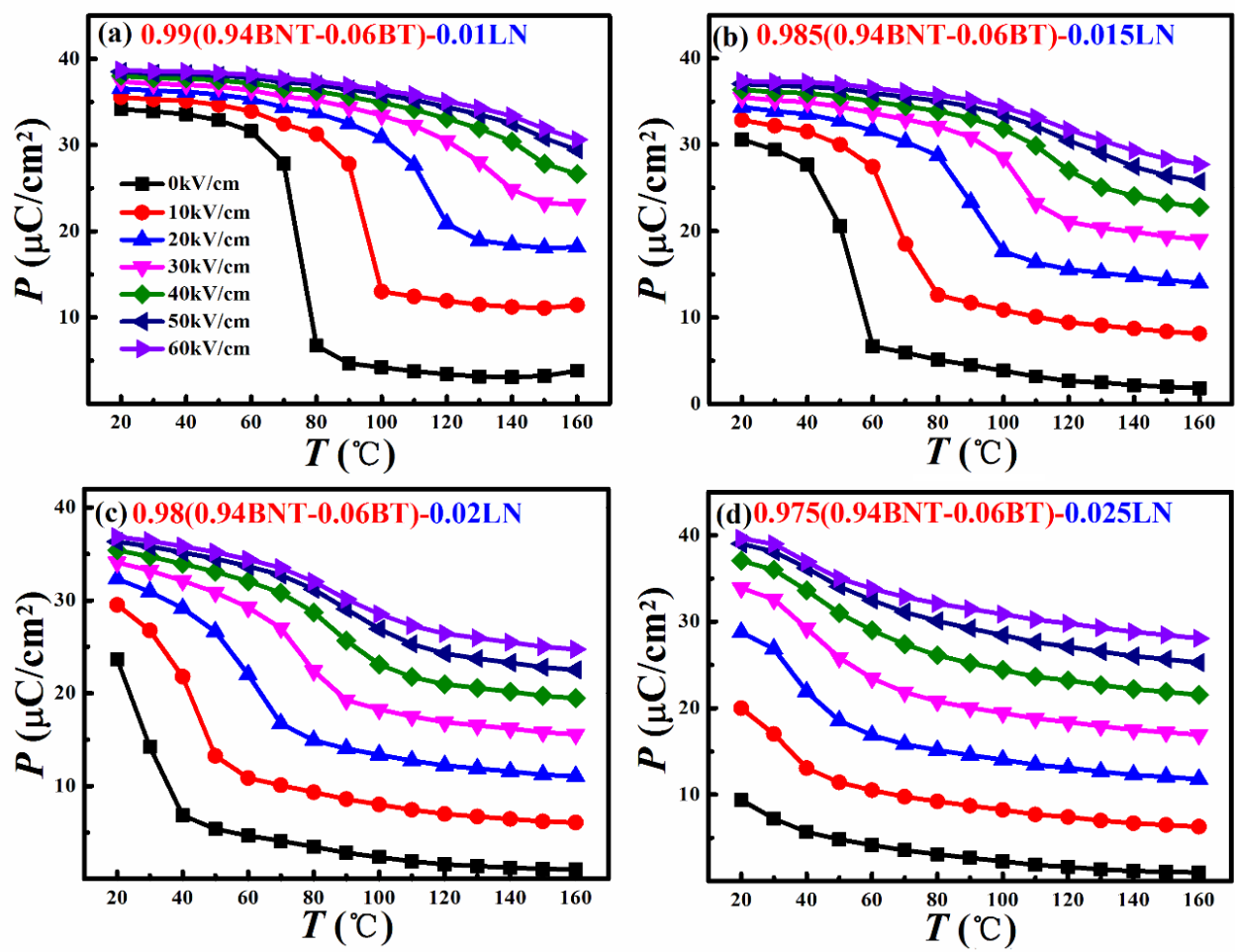

Figure 2.The relationship between the maximum polarization of (1-x)(0.94BNT0.06BT)-xLiNbO 3 and temperature in different electric fields: (a) $0.01 \mathrm{LiNbO}_{3}$;(b) 0.015 $\mathrm{LiNbO}_{3} ;$ (c) $0.02 \mathrm{LiNbO}_{3}$;(d) $0.025 \mathrm{LiNbO}_{3}$.

As shown in Figure 3, the pyroelectric coefficient is obtained by deriving the maximum polarization intensity against temperature for different electric fields of the data in Figure 2. The peak value can be seen in all the four graphs in Figure3. Moreover, the peak changes with the voltage and temperature. This is the same as a conclusion drawn in the previous study ${ }^{[9]}$ that the transition between the ferroelectric phase and the relextor phase transitions from electric field to electric field. As can be seen in Figure 3(a), the material $0.99(0.94 \mathrm{BNT}-0.06 \mathrm{BT})-0.01 \mathrm{LiNbO}_{3}$ has a peak value of about $70^{\circ} \mathrm{C}$ at $0 \mathrm{kV} / \mathrm{cm}$. This is the same as a conclusion drawn in the previous study ${ }^{[9]}$ that in the polarized dielectric temperature spectrum, the temperature is $74^{\circ} \mathrm{C}$ during the transition from the ferroelectric phase to the relaxor phase. As the electric field increases to 10 , 
$20,30,40$ and $50 \mathrm{kV} / \mathrm{cm}$, the peaks of the material move to higher temperature, reaching $90^{\circ} \mathrm{C}, 110^{\circ} \mathrm{C}, 130^{\circ} \mathrm{C}, 140^{\circ} \mathrm{C}$ and $150^{\circ} \mathrm{C}$, respectively. However, the transition temperature is basically unchanged at 50 and $60 \mathrm{kV} / \mathrm{cm}$. This is because the transition between the ferroelectric phase and the relaxor phase is a strain caused by the electric field, and when a certain threshold is reached, this phase transition has been completed, with the electric field continuing to increase. No change in the phase transition peak will be found. This is similar to the rule of phase transition with $\mathrm{LiNbO}_{3}$ doping. Similarly, there are also reports that in $\mathrm{BNT}_{-} \mathrm{BaTiO}_{3}(\mathrm{BT})$, the temperature rises as the electric field increases during the transition from the ferroelectric phase to the relaxor phase $^{[5,12]}$. The same trend can be seen in Figure 3(b), (c) and (d). When the $\mathrm{LiNbO}_{3}$ doping content is equal to $0.015 \mathrm{~mol}, 0.02 \mathrm{~mol}$ and $0.025 \mathrm{~mol}$, the peak temperature at 0 $\mathrm{kV} / \mathrm{cm}$ is also basically the same as the temperature measured during the transition from the ferroelectric phase to the relaxor phase in the polarized dielectric temperature spectrum in The previous study ${ }^{[9]}$. As the electric field increases, the transition temperature increases correspondingly. When the threshold field appears, the phase transition temperature remains basically unchanged. This indirectly proves that this type of peak transformation is also caused by the transition from the ferroelectric phase to the relaxor phase. Similarly, phase transition helps to improve the electrocaloric effect of the material. 

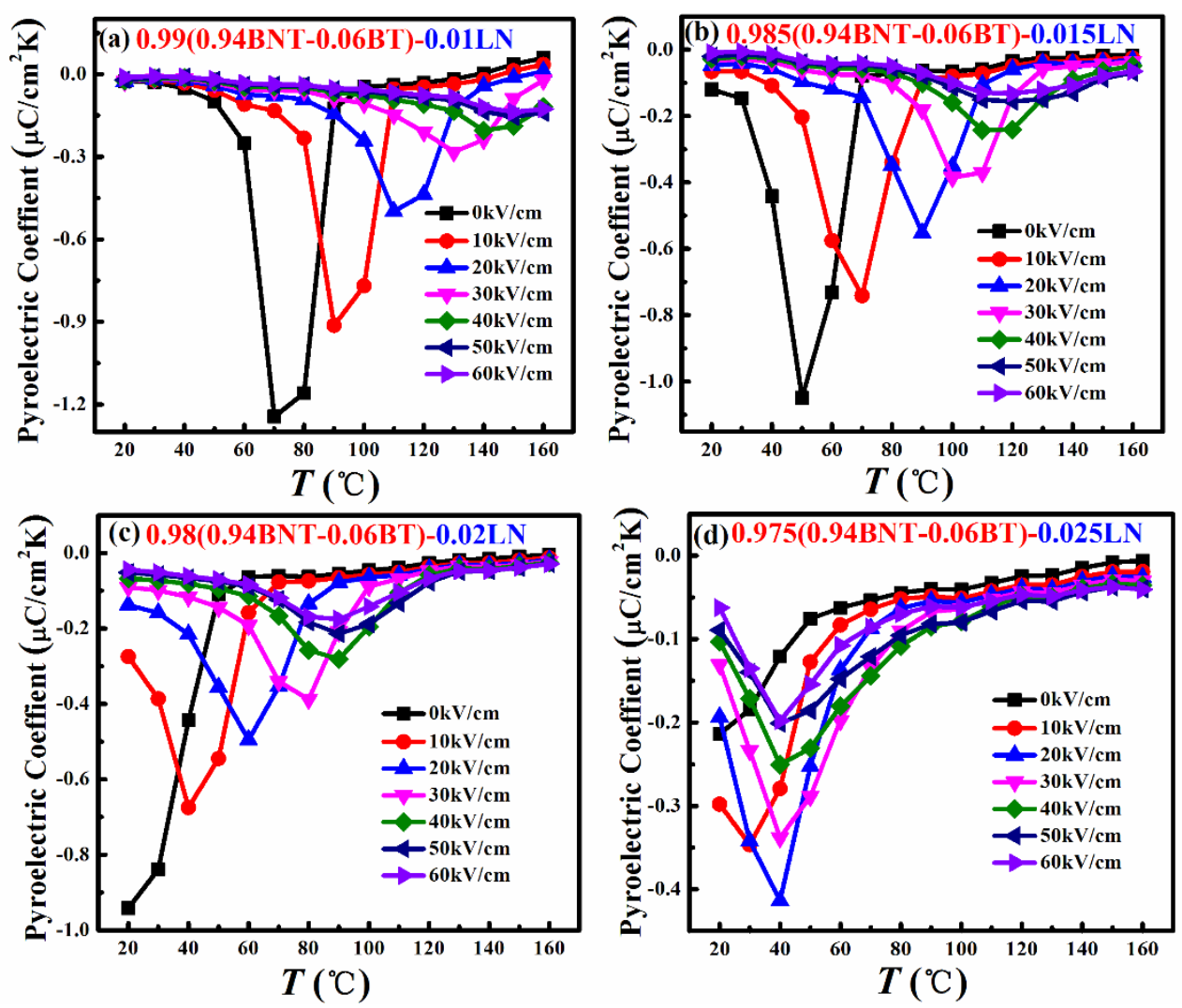

Figure 3. The relationship between the pyroelectric coefficient of $(1-\mathrm{x})(0.94 \mathrm{BNT}-$ 0.06BT)-xLiNbO 3 and temperature in different electric fields: (a) $0.01 \mathrm{LiNbO}_{3}$;(b) $0.015 \mathrm{LiNbO}_{3} ;$ (c) $0.02 \mathrm{LiNbO}_{3} ;$ (d) $0.025 \mathrm{LiNbO}_{3}$.

Since the calculation formula for adiabatic temperature changes involves the density and specific heat capacity of material samples, we tested the volume density using Archimedes' method of drainage and tested the density and specific heat capacity of the material using DSC. The volume density of piezoelectric ceramic samples was determined according to the national standard GB2413-81, i.e., Archimedes principle: When an object is totally or partially immersed in a fluid, it experiences an upthrust equal to the weight of the fluid displaced. The force is straight up and passes through the weight of the fluid displaced. The ratio of the magnitude of the force to the density of the fluid is the volume density of the sample. The calculation formula is: 


$$
\rho=\frac{\omega_{0}}{\omega_{1}-\omega_{2}} \rho_{H_{2} O}
$$

where $\omega_{0}$ represents the weight of the sample weighed in the dried air; $\omega_{1}$ represents the weight of the sample weighed in the air after full water absorption; $\omega_{2}$ represents the weight of the sample weighed in water after full water absorption; $\rho_{\mathrm{H}_{2} \mathrm{O}}$ represents the density of water. The test result is shown in Figure 4(a). As can be seen, when the content of $\mathrm{LiNbO}_{3}$ is $0.01,0.015,0.02$ and $0.025 \mathrm{~mol}$, the density is 5.82, $5.80,5.90$ and $5.88 \mathrm{~g} / \mathrm{cm}^{3}$, respectively.

Specific heat capacity refers to the amount of heat required for every $1^{\circ} \mathrm{C}$ rise in the temperature of an object with a weight of $1 \mathrm{~kg}$. The specific values are shown in Figure 4(b). As can be seen, the specific heat capacity shows a different trend as the doping content of $\mathrm{LiNbO}_{3}$ changes, but the overall value is basically the same. All the values within the temperature range are between 450 and $500 \mathrm{~J} /(\mathrm{kg} \cdot \mathrm{K})$.
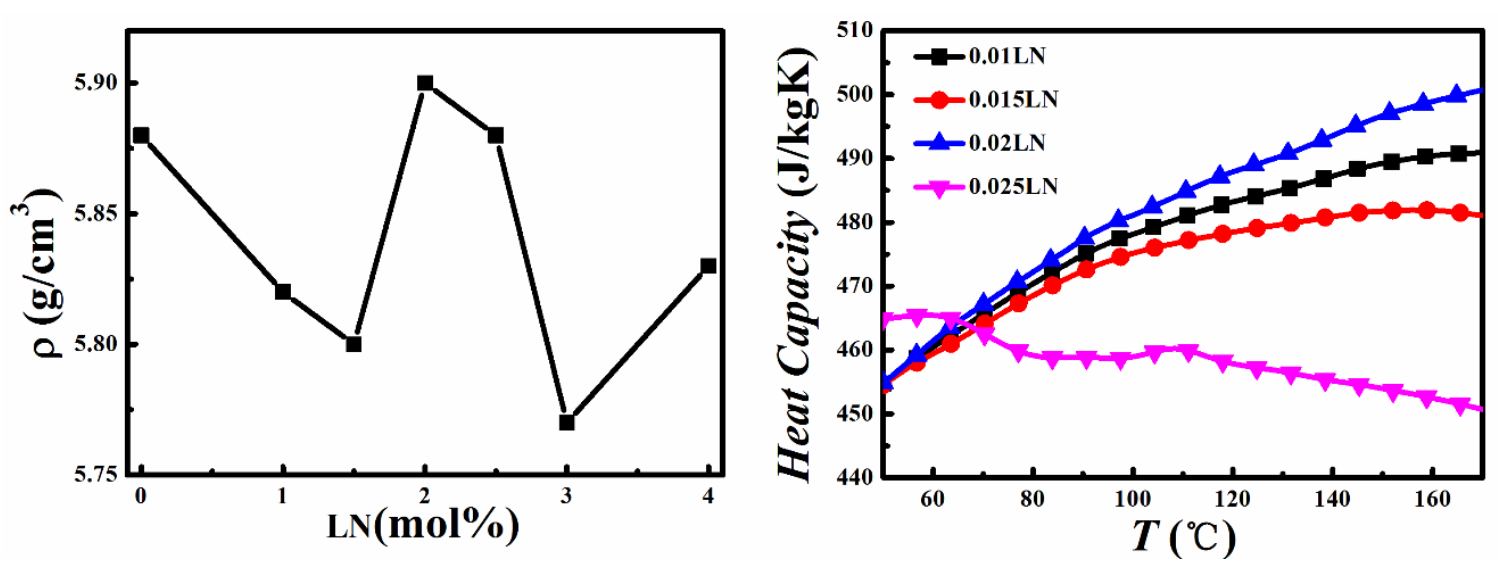

Figure 4. Density and specific heat capacity of (1-x)(0.94BNT-0.06BT)-xLiNbO3: (a) density; (b) specific heat capacity.

According to the density measured above, the specific heat capacity and pyroelectric coefficient are calculated using the formula for adiabatic temperature changes: 


$$
\Delta T=-\frac{T}{\rho} \int_{E_{1}}^{E_{2}} \frac{1}{C_{E}}\left(\frac{\partial P}{\partial T}\right)_{E} d E
$$

Figure 5 shows the adiabatic temperature changes of all different component points at $10,20,30,40,50$ and $60 \mathrm{kV} / \mathrm{cm}$. As can be seen from the data in the figure, the adiabatic temperature changes of all the components are positive. For $0.99(0.94 \mathrm{BNT}$ 0.06BT)-0.01 $\mathrm{LiNbO}_{3}$, the temperature measured during the transition between the ferroelectric phase and the relaxor phase differs from electric field to electric field, and the change trend is basically the same as that of the pyroelectric coefficient. Therefore, the maximum temperature range of adiabatic temperature changes differs, too, from electric field to electric field, with the adiabatic temperature rising from $90^{\circ} \mathrm{C}$ at $10 \mathrm{kV} / \mathrm{cm}$ to $150^{\circ} \mathrm{C}$ at $60 \mathrm{kV} / \mathrm{cm}$. However, the peak value is basically the same, i.e., $\Delta \mathrm{T}_{\max } \approx 1.2 \mathrm{~K}$. For $0.985(0.94 \mathrm{BNT}-0.06 \mathrm{BT})-0.015 \mathrm{LiNbO}_{3}$, its maximum adiabatic temperature change also differs from electric field to electric field. When the temperature reaches $100 \sim 110^{\circ} \mathrm{C}$ at $30 \mathrm{kV} / \mathrm{cm}$, the maximum temperature change $\Delta \mathrm{T}_{\max } \approx 1.5 \mathrm{~K} .100 \sim 110^{\circ} \mathrm{C}$ is the critical temperature point for the transition from the mixed ferroelectric phase and relaxor phase to the relaxor phase. Therefore, because the adiabatic temperature change of the material has a maximum value due to relaxor phase transition. For $0.98(0.94 \mathrm{BNT}-0.06 \mathrm{BT})-0.02 \mathrm{LiNbO}_{3}$, its maximum adiabatic temperature change also differs from electric field to electric field. When the temperature reaches $80 \sim 90^{\circ} \mathrm{C}$ at 40,50 and $60 \mathrm{kV} / \mathrm{cm}$, the maximum temperature change $\Delta \mathrm{T}_{\max } \approx 1.5 \mathrm{~K}$. For $0.975(0.94 \mathrm{BNT}-0.06 \mathrm{BT})-0.025 \mathrm{LiNbO}_{3}$, the variable field analysis in the previous study ${ }^{[9]}$ shows that when the material is at room temperature and below $60 \mathrm{kV} / \mathrm{cm}$, its performance characteristics are all manifested as relaxor phase 
characteristics, so the maximum adiabatic temperature change of the material stabilizes at the same temperature point. At about $40^{\circ} \mathrm{C}$ and $60 \mathrm{kV} / \mathrm{cm}$, the material has the maximum adiabatic temperature change $\Delta \mathrm{T}_{\max } \approx 1.4 \mathrm{~K}$. At $25^{\circ} \mathrm{C} \sim 80^{\circ} \mathrm{C}$ and $60 \mathrm{kV} / \mathrm{cm}$ the material's $\Delta \mathrm{T}$ remains greater than $0.6 \mathrm{~K}$. This shows that along with the increase in the content of $\mathrm{LiNbO}_{3}$, the temperature drops during the transition between the ferroelectric phase and the relaxor phase, reducing the maximum adiabatic temperature change point of the material to near room temperature. Moreover, maximum temperature change does not decrease too much, which is conducive to the practical application of the material.
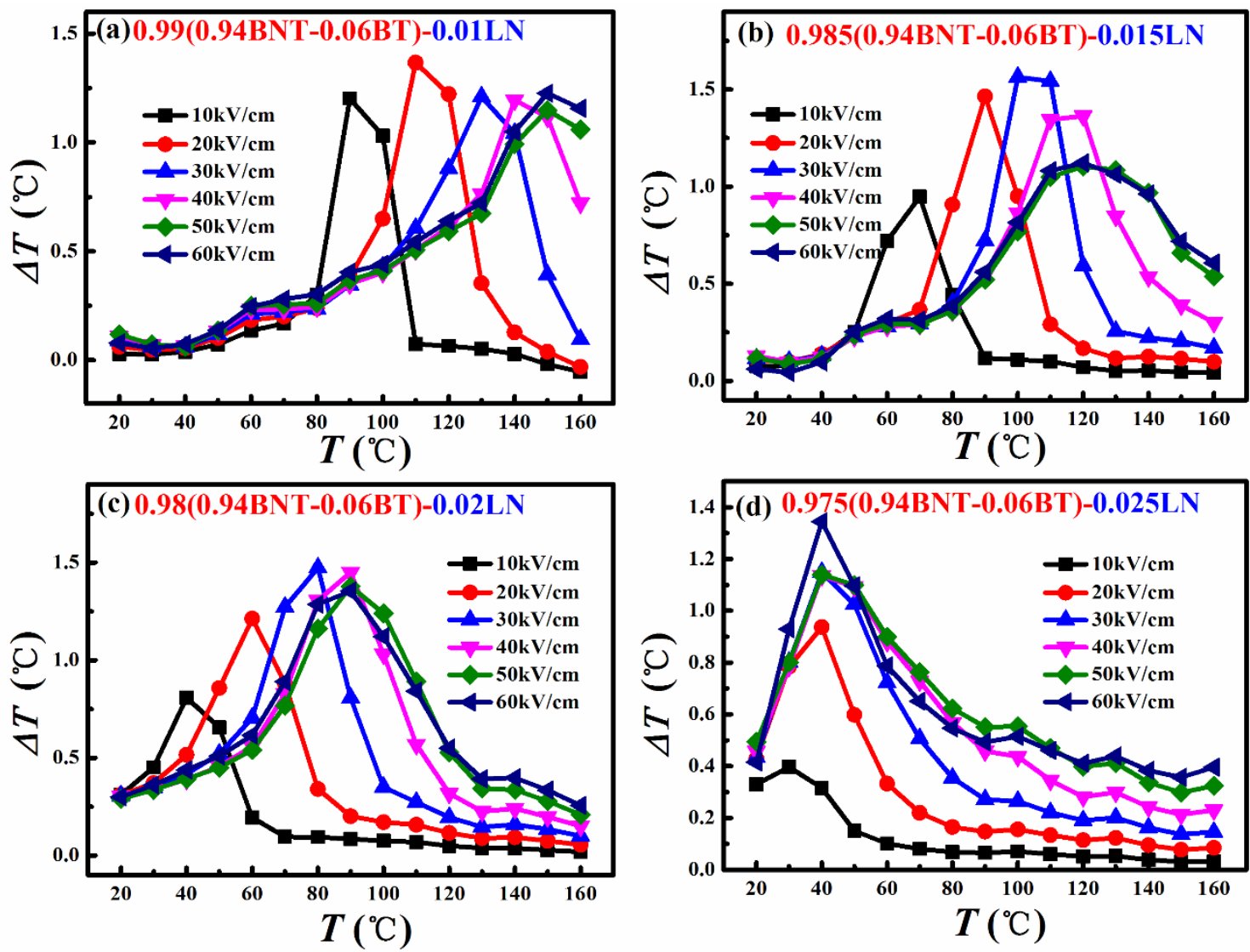

Figure 5. The relationship between the adiabatic temperature changes of (1$\mathrm{x})(0.94 \mathrm{BNT}-0.06 \mathrm{BT})-\mathrm{xLiNbO} 3$ and temperature in different electric fields: (a) 0.01 $\mathrm{LiNbO}_{3}$;(b) $0.015 \mathrm{LiNbO}_{3}$;(c) $0.02 \mathrm{LiNbO}_{3}$;(d) $0.025 \mathrm{LiNbO}_{3}$ 
Besides adiabatic temperature change, refrigeration capacity $\Delta \mathrm{T} / \Delta \mathrm{E}$ is also an important parameter in dielectric refrigeration materials. In order to compare the difference between the electric card effect of the prepared materials in this chapter and the properties of other refrigeration materials. Table 1 shows the performance of different materials. it can be seen from the data in the table that the absolute value of bulk ceramic materials is relatively low compared with thin film and single crystal materials, which is due to the high breakdown field strength of thin film and single crystal. The results show that the transition of ferroelectric phase to relaxation phase is one of the effective ways to increase the effect of Electrocaloric.

Table 1 The electrocaloric Performance of materials

\begin{tabular}{|c|c|c|c|c|c|c|}
\hline materials & $T(\mathrm{~K})$ & $\Delta T(\mathrm{~K})$ & $\Delta E(\mathrm{kV} / \mathrm{cm})$ & $\begin{array}{l}\Delta T / \Delta E(\mathrm{~K} \cdot \mathrm{cm} \\
/ \mathrm{kV})\end{array}$ & $\begin{array}{l}\text { Test } \\
\text { Mathod }\end{array}$ & Film/Ceramic \\
\hline $\mathrm{Pb}\left(\mathrm{Zr}_{0.95} \mathrm{Ti}_{0.05}\right) \mathrm{O}_{3}{ }^{[13]}$ & 499 & 12 & 480 & 0.025 & indirect & Thin film \\
\hline $\begin{array}{l}\mathrm{P}(\mathrm{VDF}-\mathrm{TrFE}) 65 / 35 \\
\mathrm{~mol}^{[14]}\end{array}$ & 353 & $\sim 12$ & 2090 & $\sim 0.006$ & indirect & Thin film \\
\hline $\mathrm{SrBi}_{2} \mathrm{Ta}_{2} \mathrm{O}_{9}^{[15]}$ & 565 & 4.93 & 600 & 0.0082 & indirect & Thin film \\
\hline $\mathrm{Pb}(\mathrm{Zr}, \mathrm{Sn}, \mathrm{Ti}) \mathrm{O}_{3}{ }^{[16]}$ & $\sim 440$ & 2.6 & 30 & 0.0086 & indirect & ceramic \\
\hline $\begin{array}{l}0.94 \mathrm{Bi}_{0.5} \mathrm{Na}_{0.5} \mathrm{TiO}_{3-} \\
0.06 \mathrm{KNbO}_{3}{ }^{[17]}\end{array}$ & 349 & 1.73 & 70 & 0.024 & indirect & ceramic \\
\hline $\mathrm{BaZr}_{0.2} \mathrm{Ti}_{0.8} \mathrm{O}_{3}{ }^{[18]}$ & 313 & 4.9 & 97 & 0.051 & direct & Thick film \\
\hline $\begin{array}{l}0.94 \mathrm{Bi}_{0.5} \mathrm{Na}_{0.5} \mathrm{TiO}_{3-} \\
0.06 \mathrm{BaTiO}_{3}{ }^{[8]}\end{array}$ & 408 & 1.5 & 50 & 0.03 & direct & ceramic \\
\hline NBBST0.10 $0^{[5]}$ & 383 & 0.72 & 40 & 0.018 & indirect & ceramic \\
\hline $0.975(0.94 \mathrm{BNT}-$ & & & & & & \\
\hline $\begin{array}{l}0.06 \mathrm{BT})- \\
0.025 \mathrm{LiNbO}_{3}\end{array}$ & 373 & 1.4 & 60 & 0.0231 & indirect & ceramic \\
\hline
\end{tabular}

\section{Conclusions}

Based on the above analysis, the following conclusions are drawn: $\mathrm{LiNbO}_{3}$ doped with the $0.94 \mathrm{BNT}-0.06 \mathrm{BT}$ ceramic material system can reduce the cooling temperature of materials. The refrigeration temperature drops from $100 \sim 140^{\circ} \mathrm{C}$ of $0.94 \mathrm{BNT}-0.06 \mathrm{BT}$ 
ceramic to $25 \sim 80^{\circ} \mathrm{C}$, achieving its cooling effect near room temperature. $\mathrm{LiNbO}_{3}$ doped with the 0.94BNT-0.06BT ceramic material system perfectly retains the excellent refrigeration performance of the material system, with the maximum adiabatic temperature change $\Delta \mathrm{T}_{\max }$ of all components greater than $1 \mathrm{~K}$.

\section{Acknowledgments}

This work was financially supported by Nanjing University of Industrial And Vocational Technology Research Project (Grant No. YK19-02-03), Natural Science Foundation of Jiangsu Province (Grant No. BK20180936), Jiangsu Province 2019" Mass entrepreneurship and innovation Plan " (Grant No. 1990502807).

\section{References}

[1] Jiang X, Luo L, Wang B, et al. Electrocaloric effect based on the depolarization transition in (1x)Bi $\mathrm{Bi}_{0.5} \mathrm{Na}_{0.5} \mathrm{TiO}_{3}-\mathrm{KKNbO}_{3}$ lead-free ceramics [J]. Ceramics International, 40 (2014) 2627-2634.

[2] Bai Y, Zheng G P, Shi S Q. Abnormal electrocaloric effect of $\mathrm{Na}_{0.5} \mathrm{Bi}_{0.5} \mathrm{TiO}_{3}-\mathrm{BaTiO}_{3}$ lead-free ferroelectric ceramics above room temperature [J]. Materials Research Bulletin, 46 (2011) 1866-1869.

[3] Zheng X C, Zheng G P, Lin Z, et al. Electro-caloric behaviors of lead-free $\mathrm{Bi}_{0.5} \mathrm{Na}_{0.5} \mathrm{TiO}_{3}-\mathrm{BaTiO}_{3}$ ceramics [J]. Journal of Electroceramics, 28 (2011) 20-26.

[4] Li Q, Wang J, Ma L, et al. Large electrocaloric effect in $\left(\mathrm{Bi}_{0.5} \mathrm{Na}_{0.5}\right)_{0.94} \mathrm{Ba}_{0.06} \mathrm{TiO}_{3}$ lead-free ferroelectric ceramics by $\mathrm{La}_{2} \mathrm{O}_{3}$ addition [J]. Materials Research Bulletin, 74 (2016) 57-61.

[5] Luo L, Jiang X, Zhang Y, et al. Electrocaloric effect and pyroelectric energy harvesting of (0.94x) $\mathrm{Na}_{0.5} \mathrm{Bi}_{0.5} \mathrm{TiO}_{3}-0.06 \mathrm{BaTiO}_{3}-\mathrm{xSrTiO}$ ceramics [J]. Journal of the European Ceramic Society, 37 (2017) 2803-2812.

[6] Zheng G-P, Uddin S, Zheng X, et al. Structural and electrocaloric properties of multiferroic- $\mathrm{BiFeO}_{3}$ doped $0.94 \mathrm{Bi}_{0.5} \mathrm{Na}_{0.5} \mathrm{TiO}_{3}-0.06 \mathrm{BaTiO}_{3}$ solid solutions [J]. Journal of Alloys and Compounds, 663 (2016) 249-255.

[7] Li F, Chen G, Liu X, et al. Phase-composition and temperature dependence of electrocaloric effect in lead-free $\mathrm{Bi}_{0.5} \mathrm{Na}_{0.5} \mathrm{TiO}_{3}-\mathrm{BaTiO}_{3}-\left(\mathrm{Sr}_{0.7} \mathrm{Bi}_{0.2}\right) \mathrm{TiO}_{3}$ ceramics [J]. Journal of the European Ceramic Society, 37 (2017) 4732-4740.

[8] Li F, Chen G, Liu X, et al. Type-I pseudo-first-order phase transition induced electrocaloric effect in lead-free $\mathrm{Bi}_{0.5} \mathrm{Na}_{0.5} \mathrm{TiO}_{3}-0.06 \mathrm{BaTiO}_{3}$ ceramics [J]. Applied Physics Letters, 110 (2017) 182904.

[9] J. Chen, Y. Wang, Y. Zhang, Y. Yang, R. Jin, Giant electric field-induced strain at room temperature in $\mathrm{LiNbO}_{3}$-doped $0.94\left(\mathrm{Bi}_{0.5} \mathrm{Na}_{0.5}\right) \mathrm{TiO}_{3}-0.06 \mathrm{BaTiO}_{3}$, Journal of the European Ceramic Society, 37 (2017) 2365-2371.

[10] Bai W, Chen D, Huang Y, et al. Electromechanical properties and structure evolution in $\mathrm{BiAlO}_{3}$ modified $\mathrm{Bi}_{0.5} \mathrm{Na}_{0.5} \mathrm{TiO}_{3}-\mathrm{BaTiO}_{3}$ lead-free piezoceramics [J]. Journal of Alloys and Compounds, 667 
(2016) 6-17.

[11] Luo L, Jiang X, Zhang Y, et al. Electrocaloric effect and pyroelectric energy harvesting of (0.94x) $\mathrm{Na}_{0.5} \mathrm{Bi}_{0.5} \mathrm{TiO}_{3}-0.06 \mathrm{BaTiO}_{3}-\mathrm{xSrTiO}_{3}$ ceramics [J]. Journal of the European Ceramic Society, 37 (2017) 2803-2812.

[12] Ge W, Maurya D, Li J, et al. Alternating and direct current field effects on the structure-property relationships in $\mathrm{Na}_{0.5} \mathrm{Bi}_{0.5} \mathrm{TiO}_{3}-\mathrm{xBaTiO}_{3}$ textured ceramics [J]. Applied Physics Letters, 102 (2013) 222905.

[13]Mischenko A S, Zhang Q, Scott J F, et al. Giant Electrocaloric Effect in Thin-Film $\mathrm{PbZr}_{0.95} \operatorname{Ti}_{0.05} \mathrm{O}_{3}[\mathrm{~J}]$. Science, 311 (2006) 1270-1271.

[14]Neese B, Chu B, Lu S G, et al. Large Electrocaloric Effect in Ferroelectric Polymers Near Room Temperature[J]. Science, 321 (2008) 821-823.

[15]Chen H, Ren T L, Wu X M, et al. Giant electrocaloric effect in lead-free thin film of strontium bismuth tantalite[J]. Applied Physics Letters, 94 (2009) 182902.

[16]Tuttle B A, Payne D A. The effects of microstructure on the electrocaloric properties of $\mathrm{Pb}(\mathrm{Zr}, \mathrm{Sn}, \mathrm{Ti}) \mathrm{O}_{3}$ ceramics[J]. Ferroelectrics, 37 (2011) 603-606.

[17]Jiang X, Luo L, Wang B, et al. Electrocaloric effect based on the depolarization transition in (1x) $\mathrm{Bi}_{0.5} \mathrm{Na}_{0.5} \mathrm{TiO}_{3}-\mathrm{xKNbO}$ lead-free ceramics[J]. Ceramics International, 40 (2014) 2627-2634.

[18] Ye H J, Qian X S, Jeong D Y, et al. Giant electrocaloric effect in $\mathrm{BaZr}_{0.2} \mathrm{Ti}_{0.8} \mathrm{O}_{3}$ thick film[J]. Applied Physics Letters, 105 (2014) 152908. 
Figures
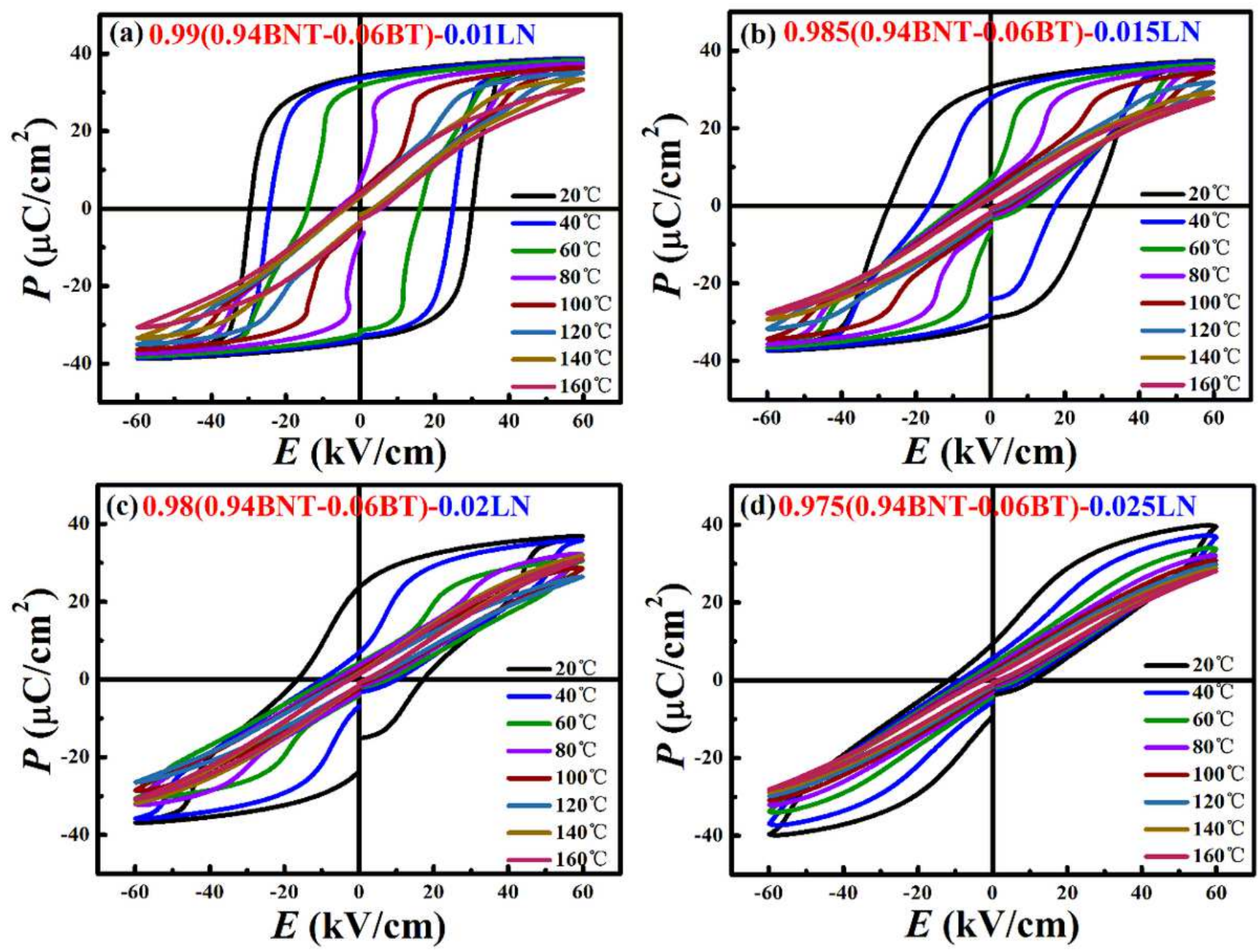

Figure 1

Variable-temperature ferroelectric hysteresis loop of (1-x)(0.94BNT-0.06BT)-xLiNbO3 at different temperatures: (a) 0.01 LiNb03; (b) 0.015 LiNb03; (c) 0.02 LiNb03; (d) 0.025 LiNb03. 

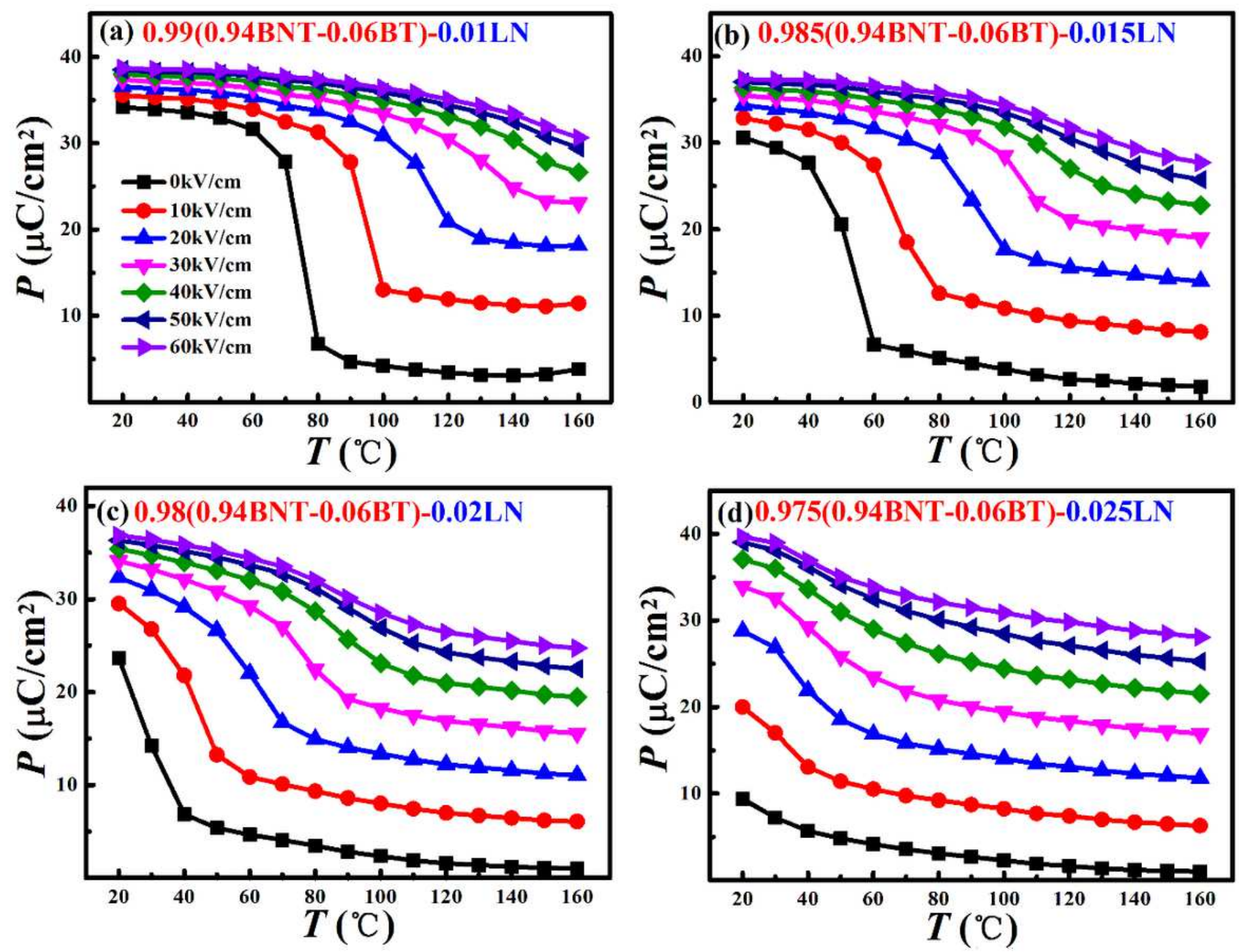

Figure 2

The relationship between the maximum polarization of (1-x)(0.94BNT-0.06BT)-xLiNb03 and temperature in different electric fields: (a) 0.01 LiNbO3;(b) 0.015 LiNb03;(c) 0.02 LiNb03;(d) 0.025 LiNb03. 

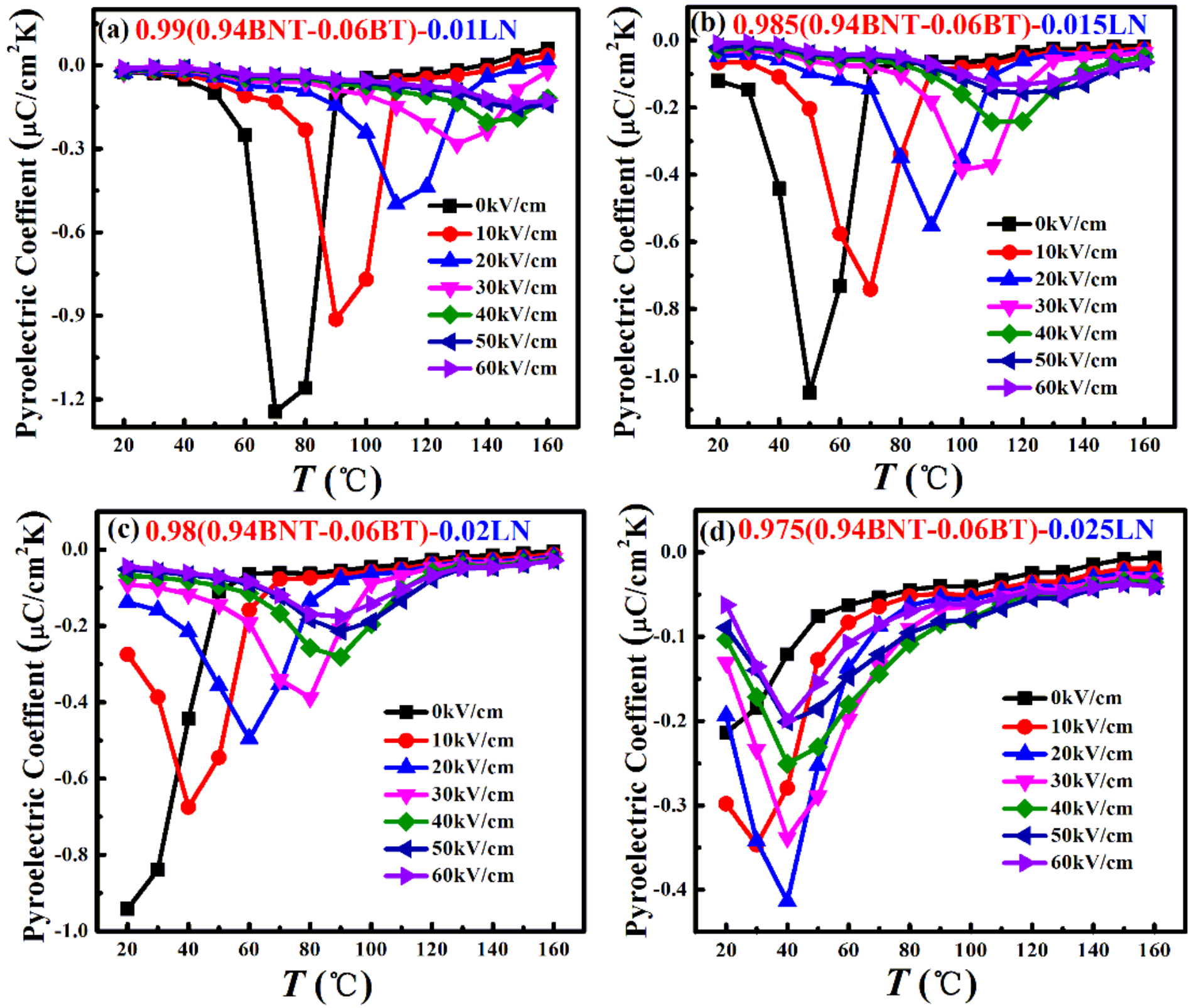

Figure 3

The relationship between the pyroelectric coefficient of (1-x)(0.94BNT-0.06BT)-xLiNb03 and temperature in different electric fields: (a) 0.01 LiNb03;(b) 0.015 LiNb03;(c) 0.02 LiNb03;(d) 0.025 LiNb03. 

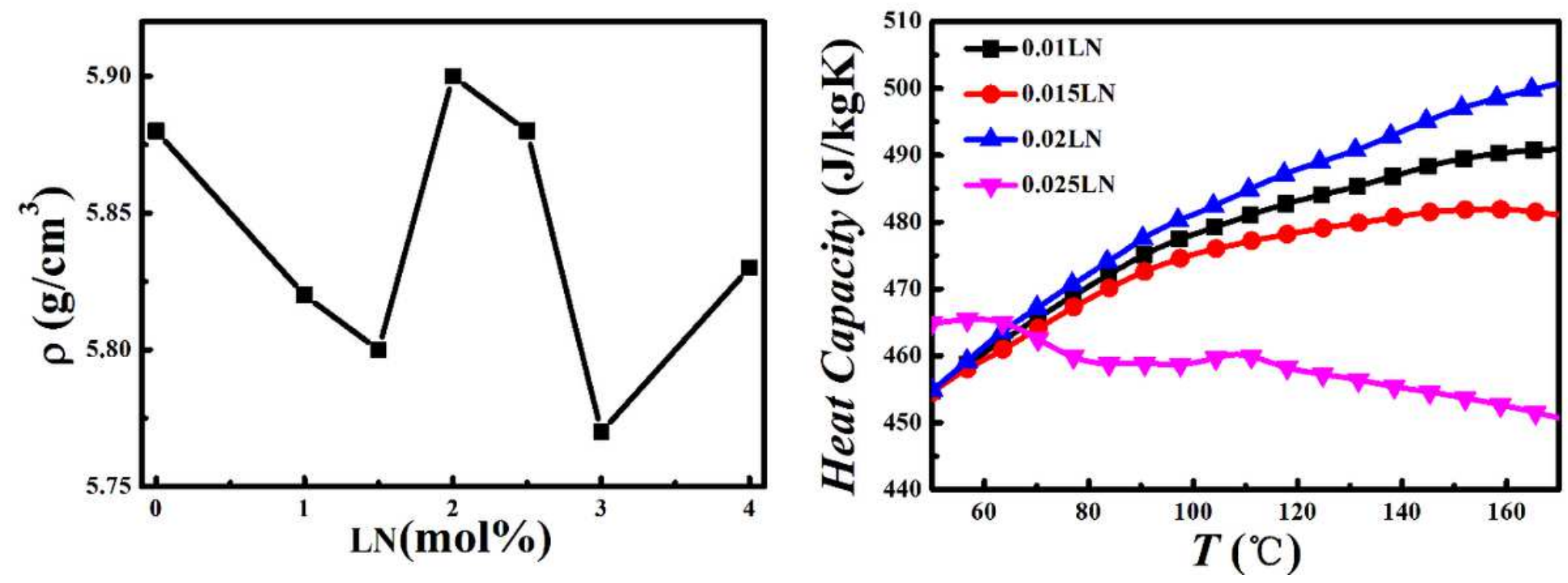

Figure 4

Density and specific heat capacity of (1-x)(0.94BNT-0.06BT)-xLiNb03: (a) density; (b) specific heat capacity.
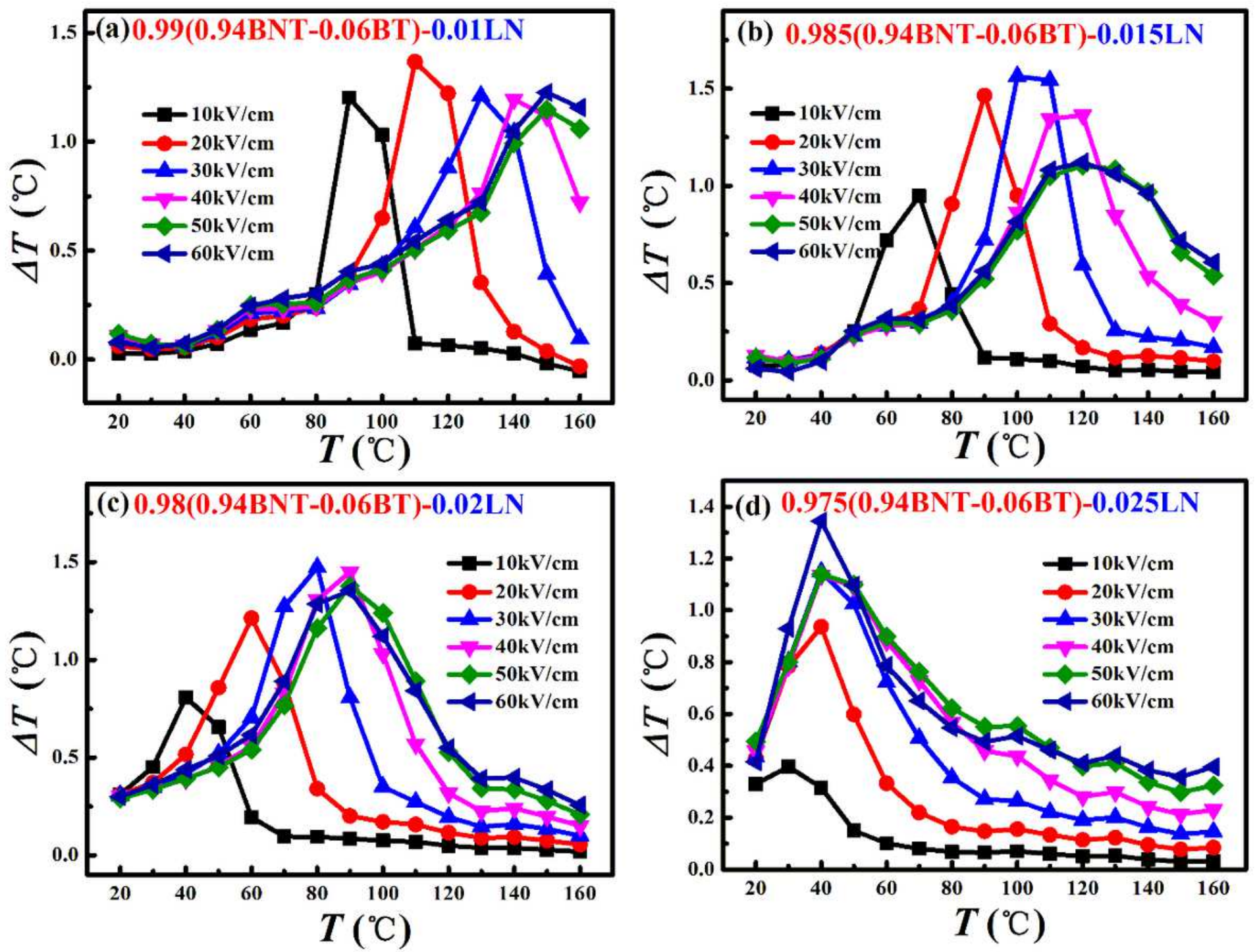


\section{Figure 5}

The relationship between the adiabatic temperature changes of $(1-\mathrm{x})(0.94 \mathrm{BNT}-0.06 \mathrm{BT})-\mathrm{xLiNbO} 3$ and temperature in different electric fields: (a) 0.01 LiNb03;(b) 0.015 LiNbO3;(c) 0.02 LiNb03;(d) 0.025 LiNbO3 